\title{
Angle and Force Hybrid Control Method for Electrohydraulic Leveling System with Independent Metering
}

\author{
Kailei Liu $\mathbb{D}$, ${ }^{1}$ Shaopeng Kang $\mathbb{D},{ }^{1}$ Zhongliang Cao $\mathbb{D},{ }^{1}$ Rongsheng Liu $\mathbb{D},^{2}$ \\ and Zhaoxuan Ding ${ }^{1}{ }^{1}$ \\ ${ }^{1}$ School of Mechanical Engineering, Jiangsu University of Technology, Changzhou 213001, Jiangsu, China \\ ${ }^{2}$ School of Intelligence Engineering, Henan Institute of Technology, Xinxiang 453000, Henan, China \\ Correspondence should be addressed to Shaopeng Kang; kangshaopengjsut@163.com
}

Received 5 October 2020; Revised 20 December 2020; Accepted 26 December 2020; Published 8 January 2021

Academic Editor: Haipeng Peng

Copyright (c) 2021 Kailei Liu et al. This is an open access article distributed under the Creative Commons Attribution License, which permits unrestricted use, distribution, and reproduction in any medium, provided the original work is properly cited.

The electrohydraulic leveling system of the hydraulic press can realize automatic leveling control function. In order to eliminate the eccentric load force accurately, an electrohydraulic leveling system with independent metering is designed. Quasi-static behavior analysis of the leveling cylinders output forces performance is applied to the electrohydraulic leveling system with independent metering. The angle and force hybrid control method is proposed, and then the AMESim/Simulink cosimulation model is built. The HSIC controller and PID controller are used in the simulation, respectively. Simulation results show that both of the leveling angle control and leveling cylinders output forces control can be realized, simultaneously, and the HSIC controller has higher rapidity and smaller overshoot than the PID controller.

\section{Introduction}

Hydraulic forming technology plays an important role in manufacturing [1]. Hydraulic large forging technology is a kind of hydraulic forming technology. Large forging parts are widely used in equipment such as metallurgical machinery, power equipment, weapons, aerospace industry, petrochemical industry, ship manufacturing, and heavy vehicles. Large forging parts are key parts of heavy machines, requiring high mechanical performance and reliable quality [2]. Therefore, higher requirements are put forward for the processing and production of large forging parts. The manufacture of large forging parts mainly relies on the large forging hydraulic presses. The hydraulic presses are extensively used in different industries because they possess a high power-to-mass ratio, fast response, high stiffness, and high load capability $[3,4]$. Therefore, the performance of large forging hydraulic presses directly affects the product quality of large forging parts.

In order to obtain higher performance of large hydraulic presses, many scholars have made many improved research studies on various aspects of large hydraulic presses [5-8]. When a large hydraulic press is working, it often happens that the deformation resistance force of the forging part tends to deviate from the center of the large hydraulic press due to the excessively deviated forging part position; as a result, the movable beam produces an inclination moment. If the inclination moment is not balanced, the beam will be inclining, which will affect the forging accuracy of the forging part and the service life of the large hydraulic press. Therefore, large hydraulic presses need to be equipped with a synchronous leveling control system to level the movable beams in real time to avoid inclination moment.

The traditional leveling control system of a large hydraulic press machine aims to arrange four hydraulic cylinders at the four corners of the movable slide; two diagonal hydraulic leveling cylinders form a group. In each group, the upper chamber or lower chamber of one cylinder is connected to the lower chamber or the upper chamber of the other cylinder. When oil is supplied to each group of hydraulic leveling cylinders, the corresponding turning torque can be generated, which can offset the inclination moment. 
Therefore, the synchronous leveling of the movable beam can be realized. However, the leveling hydraulic cylinders are symmetrically distributed and the oil circuits of the each group cylinders are connected in series, so the output forces of the two hydraulic cylinders in each group will be equal and opposite to each other. However, when the movable beam generates an inclination moment due to eccentric load, the load forces acting on each group of hydraulic leveling cylinders are not the same. Therefore, the inclination moment cannot be eliminated accurately, so it will result in low precision of forging parts and unsatisfactory balance effect. Accordingly, the traditional synchronous leveling control system of a large hydraulic machine can only realize the inclination angle control, but cannot realize separate output forces control of the hydraulic leveling cylinders.

In the traditional hydraulic system, the speed of the hydraulic cylinder can be controlled, and the chambers pressure is dependent on the external load [9]. With the development of the hydraulic technology, the independent metering system is proposed by Jansson and Palmberg, who are using four $2 / 2$ valves that independently control an actuator; it breaks the mechanical linkage and decouples the restriction [10]. Compared with the conventional hydraulic system, the independent metering system has brought many functions due to decoupling of meter-in and meter-out orifices, including regeneration functionality, float functionality, energy saving functionality, flow control functionality, and pressure functionality $[11,12]$. Thus, the development of independent metering technology is technically and economically attractive, and it can replace the traditional hydraulic technology $[13,14]$. Many previous researchers have investigated the independent metering technology. Many other available valve configurations can realize the independent metering technology, for example, five $2 / 2$ valves, two $3 / 3$ valves, and a combination of two $3 / 3$ valves and one $2 / 2$ valve [15-17]. Different valve configurations require different control logics and corresponding control methods for desired flow and pressure control.

Consequently, in order to overcome the shortcomings of the traditional synchronous leveling control system of large hydraulic press machine, this study will adopt the independent metering technology to design the novel electrohydraulic synchronous leveling control system. The angle and force hybrid control method for electrohydraulic leveling system, with independent metering of the large hydraulic press machine, is investigated in this paper.

The remainder of this paper is organized as follows. Section 2 introduces the main layout and the working principle of electrohydraulic leveling system with independent metering. Section 3 presents the output forces performance analysis of the electrohydraulic leveling system with independent metering. The angle and force hybrid control method of electrohydraulic leveling system with independent metering is proposed in in Section 4. In Section 5, the AMESim/Simulink cosimulation model of the electrohydraulic leveling system with independent metering is developed. Section 6 concludes the paper by discussing the angle and force hybrid control method applicability and further work of the electrohydraulic leveling system with independent metering.

\section{System Layout and Working Principle}

2.1. Traditional Electrohydraulic Leveling System. The principle of traditional electrohydraulic leveling system of large hydraulic press machine is shown in Figure 1. The leveling cylinders $\# 1, \# 2, \# 3$, and $\# 4$ are, respectively, installed at the four corners of the movable beam. The four leveling cylinders are divided into two groups. The leveling cylinders \# 1 and \#4 are combined into one group, and the leveling cylinders \#2 and \#3 are combined into the other group. The upper chamber of leveling cylinder \#1, the lower chamber of leveling cylinder \#4, and the port A of proportional $4 / 3$ valve $\# 2$ are connected by hydraulic pipeline, and the lower chamber of leveling cylinder \#1, the upper chamber of leveling cylinder \#4, and port B of proportional $4 / 3$ valve $\# 2$ are connected by hydraulic pipeline. The direction and speed of the leveling cylinders $\# 1$ and $\# 4$ can be adjusted by changing the input current of the proportional $4 / 3$ valve \#2. When the left position of the proportional $4 / 3$ valve \#2 is energized, the leveling cylinder \# 1 will move downward, and the leveling cylinder \#4 will move upward; as a result, one of the diagonal leveling functions can be completed. When the right position of the proportional 4/3 valve \#2 is energized, it is similar to the left position being energized. The connection manners of the cylinder $\# 2$, cylinder \#3, and switch $4 / 3$ valve $\# 1$ are the same as those of the cylinder \#1, cylinder \#4, and switch $4 / 3$ valve \#2, as is shown in Figure 1. The working principle is the same as the cylinder $\# 1$ and cylinder \#3.

As is shown in Figure 2, two groups of leveling cylinders are located on two axes of movable beam. When the forging object is not put directly below the middle of the movable beam, it will produce a reaction load force $F_{\mathrm{L}}$ on the movable beam; as a result, the movable beam will be inclined due to the load torque $M_{\mathrm{L}}$ which is produced by the load force $F_{\mathrm{L}}$. The load force $F_{\mathrm{L}}$ can be decomposed into $F_{\mathrm{L} 1}$ and $F_{\mathrm{L} 2}$ along the axes $x$ and $y$ of the movable beam, and the load torque $M_{\mathrm{L}}$ can be decomposed into $M_{\mathrm{L} 1}$ and $M_{\mathrm{L} 2}$ along the axes $x$ and $y$ of the movable beam too. When the incline of movable beam is detected by the leveling sensors, the upper piston rods of leveling cylinders \# 1 and \#3 will produce the pulling forces $F_{1}$ and $F_{3}$, and the upper piston rods of leveling cylinders \#2 and \#4 will produce the pushing forces $F_{2}$ and $F_{4}$. The forces $F_{1}, F_{3}$, $F_{2}$, and $F_{4}$ will produce the toques $M_{1}$ and $M_{2}$, which can overcome the load torques $M_{\mathrm{L} 1}$ and $M_{\mathrm{L} 2}$; as a result, the movable beam can be restored to a horizontal position.

The working principle of the two groups of leveling cylinders located on two axes of movable beam is the same, so take the leveling cylinders \#2 and \#4 for example to illustrate the working principle of the traditional electrohydraulic leveling system, as is shown in Figure 3.

The movable beam is the key element of the electrohydraulic leveling system. When the movable beam is in balance, the forces and torques conditions of movable beam can be expressed: 


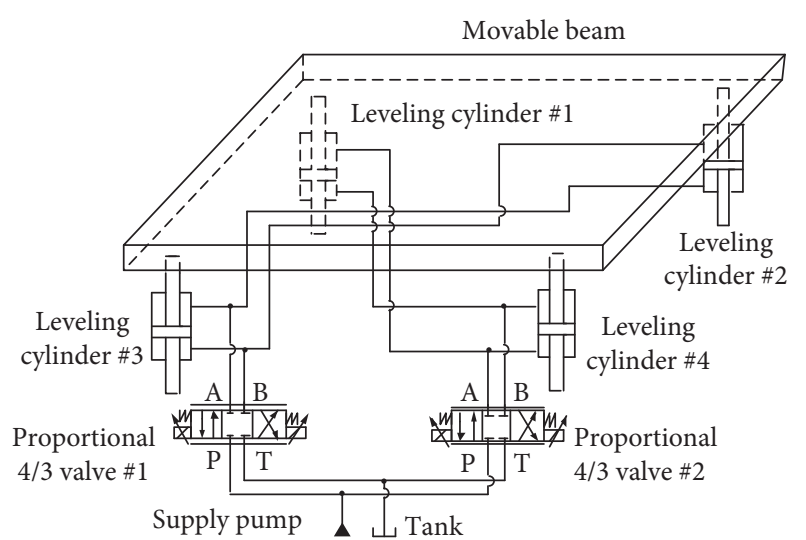

Figure 1: Principle of traditional leveling hydraulic control system.

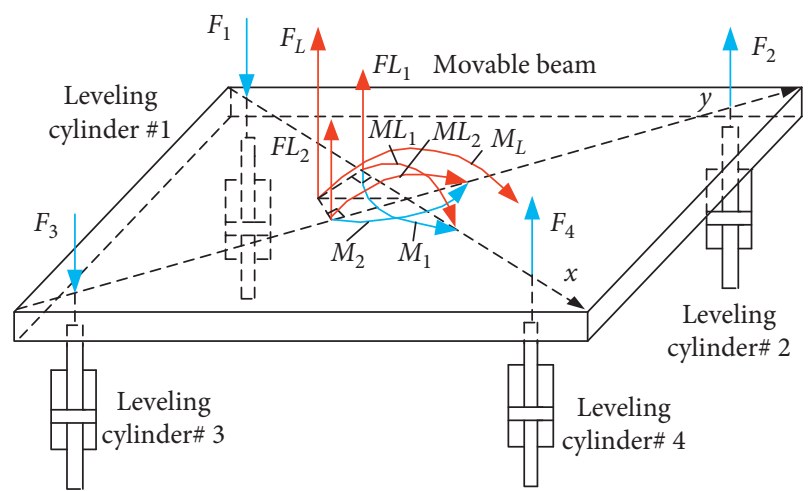

Figure 2: Eccentric load and leveling forces of movable beam.

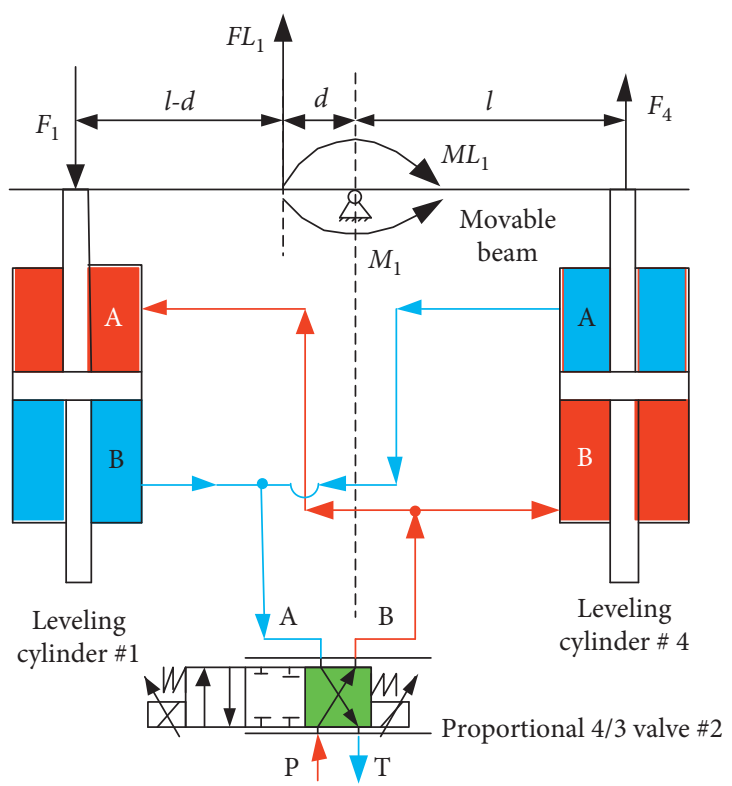

FIgURE 3: The working principle of leveling cylinders \#2 and \#4.

$$
\begin{array}{r}
F_{L 1}+F_{4}-F_{1}=0, \\
F_{1} l+F_{4} l-F_{L 1} d=0,
\end{array}
$$

where $F_{\mathrm{L} 1}$ is the decomposed load force along the axis $x, F_{1}$ is the output force of the leveling cylinder $\# 1, F_{4}$ is the output force of the leveling cylinder $\# 4, l$ is the distance of the movable beam center and leveling cylinder \#4 or \#1, and $d$ is the distance of the movable beam center and point of force $F_{\mathrm{L} 1}$.

Take (1) and (2) into derivation; the results can be obtained:

$$
\begin{aligned}
& F_{1}=-\frac{F_{L 1}(l-d)}{2 l}, \\
& F_{4}=\frac{F_{L 1}(l+d)}{2 l} .
\end{aligned}
$$

Equations (3) and (4) show that the forces $F_{1}$ and $F_{4}$ have opposite directions, and the absolute value of $F_{4}$ is greater than the absolute value of $F_{1}$.

However, the working principle of the traditional electrohydraulic leveling system is that when the movable beam is inclined, the right position of the proportional $4 / 3$ valve \#2 should be energized. The high pressure oil flows into the chamber B of leveling cylinder \#4 and the chamber A of leveling cylinder \#1 through the ports $\mathrm{P}$ and $\mathrm{B}$ of the proportional $4 / 3$ valve \#4. Then, the low pressure oil flows out of the chamber A of leveling cylinder \#4 and the chamber B of leveling cylinder \#1 through the ports $\mathrm{A}$ and $\mathrm{T}$ of the proportional $4 / 3$ valve \#4. Therefore, the value of force $F_{1}$ of leveling cylinder \#1 equals the value of force $F_{4}$ of leveling cylinder \#4, and the directions of the forces $F_{1}$ and $F_{4}$ are opposite to each other; this will produce the torque $M_{1}$ which can overcome the torque $M_{\mathrm{L} 1}$ produced by the load force $F_{\mathrm{L} 1}$.

Thus, the traditional electrohydraulic leveling system can realize the leveling control of movable beam by the produced torque $M_{1}$, but the absolute value of output force $F_{1}$ of leveling cylinder \#1 is equal to the absolute value of output force $F_{4}$ of leveling cylinder \#4. From (3) and (4), it can be seen that the force $F_{1}$ equals the calculation value of (3), the force $F_{4}$ equals the calculation value of (4), and the decomposed load force $F_{\mathrm{L} 1}$ along the axis $x$ will be eliminated absolutely. Therefore, the traditional electrohydraulic leveling system cannot eliminate the decomposed eccentric load force $F_{\mathrm{L} 1}$; it will affect the forging accuracy of forgings and the service life of hydraulic press machine.

2.2. Independent Metering System. The principle of the independent metering system is shown in Figure 4. Compared with the traditional valve control system, four spool valves, $\# 1$, \#2, \#3, and \#4, replaced the only one spool valve. When the sliding spool $s_{1}$ of valve \#1 and the sliding spool $s_{4}$ of valve \#4 are moving to the left locations with the input signals, the high pressure oil flows from the port $P$, through the spool valves \#1 and \#3, to the head chamber of the cylinder. Then, the high pressure oil pushes the cylinder piston rod to extend; as a result, the low pressure oil flows from the rod chamber of the cylinder, through the spool valves \#2 and \#4, to the port T. The flow rate of meter-in orifice of spool valve \#1 is $Q_{a}$, and the flow rate of meter-out 


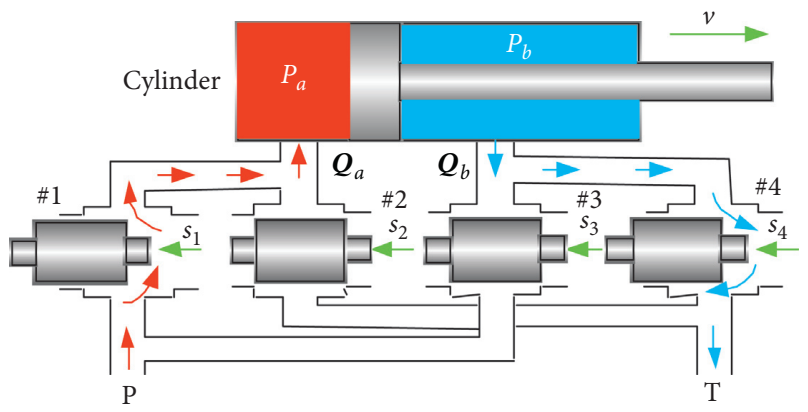

FIgURE 4: The principle of independent metering system.

orifice of spool valve \#4 is $Q_{b}$. The pressure of the cylinder head chamber is $P_{\mathrm{a}}$, and the pressure of the cylinder rod chamber is $P_{\mathrm{b}}$. Hence, compared with the conventional spool valve control system, the independent metering system has two control degrees. When the meter-in orifice and meterout orifice are regulated independently, the parameters $Q_{a}$, $Q_{b}, P_{\mathrm{a}}$, and $P_{\mathrm{b}}$ can be regulated.

\subsection{Electrohydraulic Leveling System with Independent} Metering. In order to obtain the different output forces of leveling cylinders with the same axis, $x$ or $y$, the independent metering system technology can be adopted into the design of the electrohydraulic leveling system. According to the principle of the independent metering system, the electrohydraulic leveling system with independent metering can be designed, as is shown in Figure 4.

Similarly, take the axis $x$ or $y$ for example; Figure 5 shows that the proportional $4 / 3$ valve of the traditional leveling hydraulic control system is replaced by the switch $4 / 3$ valve, and four proportional $2 / 2$ valves are used in the electrohydraulic leveling system with independent metering.

When the movable beam is moved downward by the driving cylinder, the switch $4 / 3$ valve is closed, and the four proportional $2 / 2$ valves are kept in left positions. In this situation, the working principle is the same as that of the traditional leveling hydraulic control system.

As is shown in Figure 6, when the movable beam is inclined to right, the left position of the switch $4 / 3$ valve should be energized, and the four proportional $2 / 2$ valves should be also energized. Thus, the high pressure oil flows from the supply pump, switch $4 / 3$ valve, and proportional 2/ 2 valves \#1 and \#4 to the leveling cylinder \#1 chamber $A$ and leveling cylinder \#4 chamber B. Then, it flows back from the leveling cylinder \# 1 chamber $B$, leveling cylinder \#4 chamber A, proportional $2 / 2$ valves \#2 and \#3, and left position of the switch $4 / 3$ valve to the tank. As a result, the leveling cylinder \#1 is pulling down one side of the movable beam, and the leveling cylinder \#4 is pushing up the other side of the movable beam until the movable beam returns to balance. During the entire leveling process of the movable beam, the opening ratios of the four proportional $2 / 2$ valves can be regulated, so the chambers pressure of the two leveling cylinders will be different; as a result, the absolute value of the two leveling cylinders output forces can be regulated.

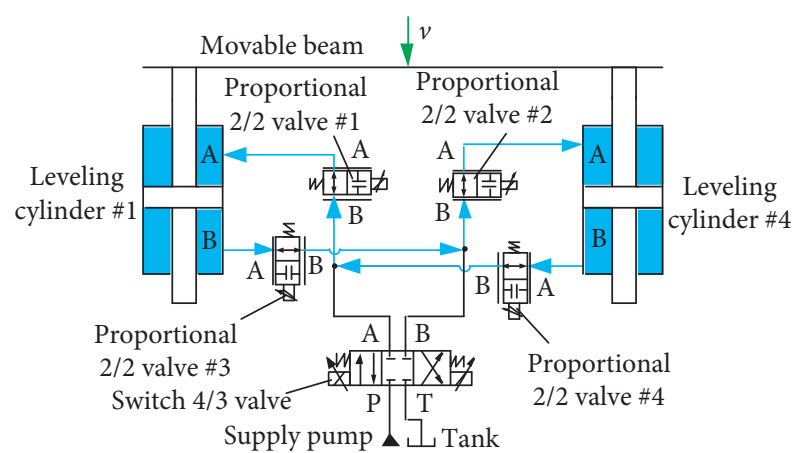

FIGURE 5: The electrohydraulic leveling system with independent metering.

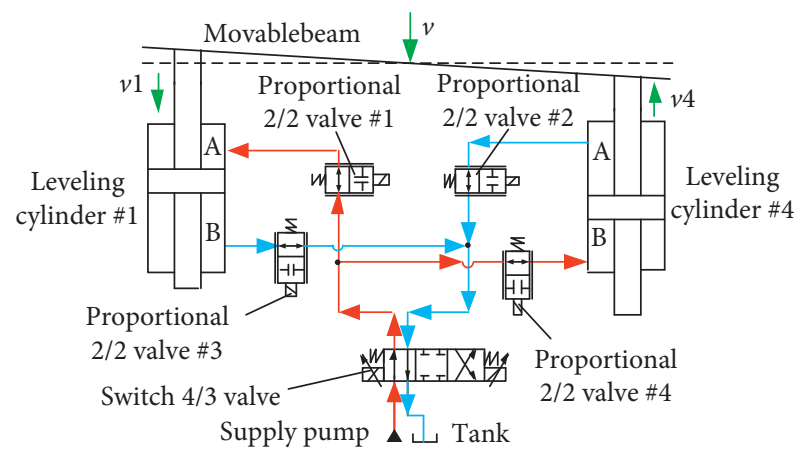

FIGURE 6: The working principle of electrohydraulic leveling system with independent metering.

\section{Output Forces Performance Analysis}

In this section, the fluid compressibility and the dynamic effects are also ignored. The electrohydraulic leveling system with independent metering, as is shown in Figure 5, can be simplified as is shown in Figure 7. It can be seen that the inflow rate $Q_{\text {in }}$ and outflow rate $Q_{b}$ are controlled by the switch $4 / 3$ valve, and the flow rates $Q_{1}, Q_{2}, Q_{3}$, and $Q_{3}$ are separately controlled by the proportional $2 / 2$ valves \#1, \#2, $\# 3$, and \#4. Accordingly, consider that the movable beam is inclined to the right, for example, and it is similar to the movable beam being inclined to the left.

The actual inclination angle can be expressed as follows:

$$
\theta_{a}=\arctan \left(\frac{x}{l}\right)
$$

where $\theta_{a}$ is the actual inclination angle, $x$ is the moving displacement of leveling cylinders \#1 and \#4.

Assume that the meter-in parameters and meter-out parameters of switch $4 / 3$ valve are the same. The inflow rate $Q_{\text {in }}$ and outflow rate $Q_{b}$ can be expressed:

$$
\begin{gathered}
Q_{\text {in }}=C_{\mathrm{ds}} W_{\mathrm{s}} x_{\mathrm{s}} K_{\mathrm{s}} \sqrt{\frac{2\left(P_{\mathrm{s}}-P_{\mathrm{a}}\right)}{\rho}}, \\
Q_{\text {out }}=C_{\mathrm{ds}} W_{\mathrm{s}} x_{\mathrm{s}} K_{\mathrm{s}} \sqrt{\frac{2\left(P_{\mathrm{b}}-P_{0}\right)}{\rho}},
\end{gathered}
$$




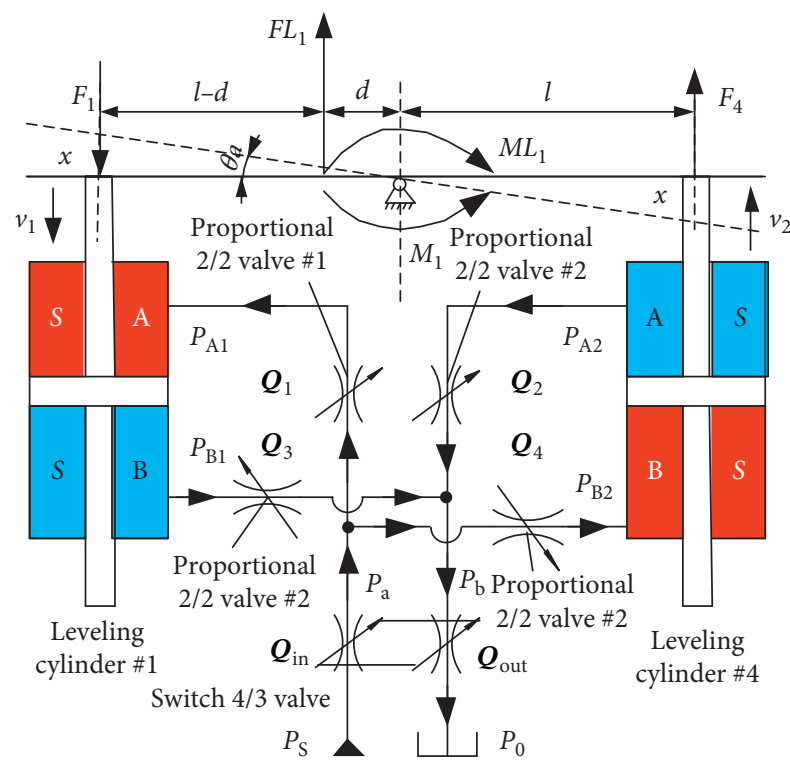

FIGURE 7: : Simplified schematic of electrohydraulic leveling system with independent metering.

where $C_{\mathrm{ds}}$ is the flow coefficient of the switch $4 / 3$ valve, $W_{\mathrm{s}}$ is the area gradient of the switch $4 / 3$ valve, $x_{\mathrm{s}}$ is the maximum displacement of the switch $4 / 3$ valve sliding spool, $K_{\mathrm{s}}$ is the opening ratio of the switch $4 / 3$ valve, $P_{\mathrm{s}}$ is the supply pump pressure, $P_{0}$ is the pressure of the tank, $P_{\mathrm{a}}$ is the pressure of port A of the switch $4 / 3$ valve, $P_{\mathrm{b}}$ is the pressure of port B of the switch $4 / 3$ valve, and $\rho$ is the density of the hydraulic fluid.

The output forces $F_{1}$ and $F_{4}$ can be expressed as follows:

$$
\begin{aligned}
& F_{1}=P_{\mathrm{A} 1} S-P_{\mathrm{B} 1} S, \\
& F_{4}=P_{\mathrm{A} 2} S-P_{\mathrm{B} 2} S,
\end{aligned}
$$

where $F_{1}$ is the output force of the leveling cylinder $\# 1, F_{4}$ is the output force of the leveling cylinder $\# 4, P_{\mathrm{A} 1}$ is the chamber A pressure of the leveling cylinder $\# 1, P_{\mathrm{B} 1}$ is the chamber $\mathrm{B}$ pressure of the leveling cylinder $\# 1, P_{\mathrm{A} 2}$ is the chamber A pressure of the leveling cylinder $\# 2, P_{\mathrm{B} 2}$ is the chamber B pressure of the leveling cylinder $\# 2$, and $S$ is the area of the piston chambers of the leveling cylinders \#1 and $\# 2$.

Take (3), (4), (7), and (8) into derivation; the results can be obtained:

$$
\frac{l-d}{l+d}=\frac{P_{\mathrm{B} 1}-P_{\mathrm{A} 1}}{P_{\mathrm{A} 2}-P_{\mathrm{B} 2}}
$$

According to the continuity equation, the inflow rate $Q_{\text {in }}$ and outflow rate $Q_{\mathrm{b}}$ can be also expressed:

$$
\begin{aligned}
Q_{\text {in }} & =Q_{1}+Q_{4}, \\
Q_{\text {out }} & =Q_{2}+Q_{3},
\end{aligned}
$$

where $Q_{1}$ is the flow rate of the proportional 2/2 valve \#1, $Q_{2}$ is the flow rate of the proportional 2/2 valve \#2, $Q_{3}$ is the flow rate of the proportional $2 / 2$ valve \#3, and $Q_{4}$ is the flow rate of the proportional $2 / 2$ valve \#4.

As the leveling cylinders \#1 and \#2 are symmetrical double rod piston cylinders, flow rates can also be expressed:

$$
\begin{gathered}
Q_{\text {in }}=Q_{\text {out }}, \\
Q_{1}=Q_{3}, \\
Q_{2}=Q_{4} .
\end{gathered}
$$

Assume that the intrinsic parameters of the proportional $2 / 2$ valves $\# 1, \# 2, \# 3$, and $\# 4$ are the same. According to the continuity equation, the inflow rates $Q_{1}, Q_{2}, Q_{3}$, and $Q_{4}$ can be also expressed:

$$
\begin{aligned}
& Q_{1}=C_{\mathrm{dp}} W_{\mathrm{p}} x_{\mathrm{p}} K_{1} \sqrt{\frac{2\left(P_{\mathrm{a}}-P_{\mathrm{A} 1}\right)}{\rho},} \\
& Q_{2}=C_{\mathrm{dp}} W_{\mathrm{p}} x_{\mathrm{p}} K_{2} \sqrt{\frac{2\left(P_{\mathrm{A} 2}-P_{\mathrm{b}}\right)}{\rho}}, \\
& Q_{3}=C_{\mathrm{dp}} W_{\mathrm{p}} x_{\mathrm{p}} K_{3} \sqrt{\frac{2\left(P_{\mathrm{B} 1}-P_{\mathrm{b}}\right)}{\rho}}, \\
& Q_{4}=C_{\mathrm{dp}} W_{\mathrm{p}} x_{\mathrm{p}} K_{4} \sqrt{\frac{2\left(P_{\mathrm{a}}-P_{\mathrm{B} 2}\right)}{\rho}},
\end{aligned}
$$

where $C_{\mathrm{dp}}$ is the flow coefficient of the four proportional $2 / 2$ valves, $W_{\mathrm{p}}$ is the area gradient of the four proportional $2 / 2$ valves, $x_{\mathrm{s}}$ is the maximum displacement of the four proportional $2 / 2$ valves' sliding spools, and $K_{1}, K_{2}, K_{3}$, and $K_{4}$ are the opening ratios of the proportional $2 / 2$ valves \#1, \#2, $\# 3$, and \#4.

Take (12)-(17) into derivation; the results can be obtained:

$$
\begin{aligned}
& \frac{K_{1}}{K_{3}}=\sqrt{\frac{P_{\mathrm{B} 1}-P_{\mathrm{b}}}{P_{\mathrm{a}}-P_{\mathrm{A} 1}}}, \\
& \frac{K_{2}}{K_{4}}=\sqrt{\frac{P_{\mathrm{a}}-P_{\mathrm{B} 2}}{P_{\mathrm{A} 2}-P_{\mathrm{b}}}} .
\end{aligned}
$$

Take (7), (8), (18), and (19) into derivation; the results can be obtained:

$$
\begin{aligned}
& \frac{K_{3}}{K_{1}}=\sqrt{\frac{\left(P_{\mathrm{A} 1}-P_{\mathrm{a}}\right) S}{F_{1}+\left(P_{\mathrm{b}}-P_{\mathrm{A} 1}\right) S}}, \\
& \frac{K_{4}}{K_{2}}=\sqrt{\frac{\left(P_{\mathrm{A} 2}-P_{\mathrm{b}}\right) S}{F_{4}+\left(P_{\mathrm{a}}-P_{\mathrm{A} 2}\right) S}} .
\end{aligned}
$$

Equation (20) shows that the ratio between the opening ratios $K_{1}$ and $K_{3}$ is related to the output force $F_{1}$, pressures $P_{\mathrm{a}}$ and $P_{\mathrm{b}}$, and piston chamber $S$. 
Take (9), (18), and (19) into derivation; the results can be obtained:

$$
\begin{aligned}
& P_{\mathrm{A} 1}=K_{\mathrm{B} 2} P_{\mathrm{B} 2}+K_{\mathrm{a} 1} P_{\mathrm{a}}+K_{\mathrm{b} 1} P_{\mathrm{b}}, \\
& P_{\mathrm{B} 1}=K_{\mathrm{A} 2} P_{\mathrm{A} 2}+K_{\mathrm{a} 2} P_{\mathrm{a}}+K_{\mathrm{b} 2} P_{\mathrm{b}}, \\
& K_{\mathrm{B} 2}=\frac{(l-d) K_{3}^{2} K_{4}^{2}}{(l+d)\left(K_{1}^{2}+K_{3}^{2}\right) K_{2}^{2}}, \\
& K_{\mathrm{A} 2}=\frac{(l-d)\left(K_{2}^{2}+K_{4}^{2}\right) K_{1}^{2}}{(l+d)\left(K_{1}^{2}+K_{3}^{2}\right) K_{4}^{2}} \\
& K_{\mathrm{a} 1}=\frac{(l+d) K_{1}^{2} K_{2}^{2}-(l-d) K_{3}^{2} K_{4}^{2}}{l+d}, \\
& K_{\mathrm{a} 2}=\frac{(l+d) K_{1}^{2} K_{4}^{2}-(l-d) K_{1}^{2} K_{4}^{2}}{(l+d)\left(K_{1}^{2}+K_{3}^{2}\right) K_{4}^{2}}, \\
& K_{\mathrm{b} 1}=\frac{(l+d) K_{2}^{2} K_{3}^{2}-(l-d) K_{2}^{2} K_{3}^{2} K_{4}^{2}}{l+d}, \\
& K_{\mathrm{b} 2}=\frac{(l+d) K_{3}^{2} K_{4}^{2}-(l-d) K_{1}^{2} K_{2}^{2}}{(l+d)\left(K_{1}^{2}+K_{3}^{2}\right) K_{4}^{2}},
\end{aligned}
$$

It can be seen that (22), (24), (26), and (28) are related to the opening ratios $K_{1}, K_{2}, K_{3}$, and $K_{4}$. The pressures $P_{\mathrm{b}}$ and $P_{\mathrm{b}}$ can be regarded as constant parameters when the supply pump pressure $P_{\mathrm{S}}$ is invariable. Hence, the relationship between the pressures $P_{\mathrm{A} 1}$ and $P_{\mathrm{B} 2}$ is dependent on the opening ratios $K_{1}, K_{2}, K_{3}$, and $K_{4}$. Similarly, (23), (25), (27), and (29) show that the relationship between the pressures $P_{\mathrm{B} 1}$ and $P_{\mathrm{A} 2}$ is also dependent on the opening ratios $K_{1}, K_{2}$, $K_{3}$, and $K_{4}$.

Equations (23) and (24) can also be used in (7) and (8). Equations (7) and (8) show that the output forces $F_{1}$ and $F_{2}$ can be regulated by the opening ratios $K_{1}, K_{2}, K_{3}$, and $K_{4}$. Thus, compared with the traditional electrohydraulic leveling system, the electrohydraulic leveling system with independent metering can not only regulate the velocity of leveling cylinders, but also regulate the output forces of leveling cylinders.

\section{Angle and Force Hybrid Control Design}

4.1. Overall Control Strategy Design. Similarly, take the axis $x$ or $y$ for example; Figure 8 shows the overall angle and force hybrid control strategy for electrohydraulic leveling system with independent metering. The electrohydraulic leveling system with independent metering is controlled by angle and force hybrid control system.

In order to achieve the angle and force hybrid control effect, many sensors should be used in the electrohydraulic leveling system with independent metering. It can be seen from Figure 8 that two force sensors, which are mounted on the pistons of leveling cylinders \#1, \#2, \#3, and \#4, can detect the output forces. Two inclination sensors, which are mounted on the axes $x$ and $y$ of the movable beam, can detect the inclination angles. Force sensors and displacement sensors are distributed on the axes $x$ and $y$ of the movable beam, which can detect the decomposed load forces $F_{\mathrm{L} 1}$ and $F_{\mathrm{L} 2}$ and the distance $d$.

In the angel and force hybrid control system, there are two control modules and an output value conversion module. Two control modules are leveling angle controller module and force controller module. The leveling angle controller module is controlling the movable beam to ensure that it is in a horizontal state, and two force controller modules are controlling the output forces of cylinders to ensure that they are consistent with the decomposed load forces. The output value conversion module is converting the output signals of leveling angle controller and force controllers to the corresponding signals of the electrohydraulic leveling system with independent metering.

\subsection{Leveling Angle Control Strategy Design}

4.2.1. Angle Control Performance Analysis. Keeping the inclination angle $\theta_{\mathrm{a}}$ as 0 can ensure that the movable beam is in a horizontal position, so the aim of the leveling angle control strategy is keeping the inclination angle $\theta_{\mathrm{a}}$ as 0 ; as a result, the command angle $\theta_{c}$ is 0 . The actual inclination angle $\theta_{\mathrm{a}}$ will appear clockwise and counterclockwise, so it can be divided into clockwise leveling condition and counterclockwise leveling condition. When assuming that leveling angle $\theta_{\mathrm{a}}$ is greater than 0 , it is clockwise, and if the leveling angle $\theta_{\mathrm{a}}$ is less than 0 , it is counterclockwise.

In the clockwise leveling condition, as Figure 8 shows, the leveling angle $\theta_{\mathrm{a}}$ is greater than 0 due to the load force $F_{\mathrm{L} 1}$, so the piston of cylinder \# 1 should be retracting and the piston of cylinder \#4 should be extending, and the movable beam will be restored to a horizontal position. The left position of the switch $4 / 3$ valve should be energized, and the four proportional $2 / 2$ valves should be also proportionally controlled. The proportional $2 / 2$ valves $\# 1$ and $\# 4$ are the meter-in valves, and the proportional $2 / 2$ valves \#2 and \#3 are the meter-out valves. Equations 11-16 show that both of the meter-in valve and the meter-out valve can regulate the flow rate by changing the opening ratios $K_{1} \sim K_{4}$. Equations 19 and 20 show that the output forces $F_{1}$ and $F_{4}$ are related to the ratios $K_{1} / K_{3}$ and $K_{2} / K_{4}$. Therefore, the meter-in opening ratios $K_{1}$ and $K_{4}$ are used to regulate the inflow rates for adjusting the velocity of the cylinder pistons. Besides, the meter-out opening ratios $K_{2}$ and $K_{3}$ are used to regulate the output forces $F_{1}$ and $F_{4}$.

Similarly, in the counterclockwise leveling condition, the piston of cylinder \#1 should be retracting and the piston of cylinder \#4 should be extending. The right position of the switch $4 / 3$ valve should be energized, and the four proportional $2 / 2$ valves should be also energized. The meter-in opening ratios $K_{2}$ and $K_{3}$ are used to adjust the velocity of the cylinder pistons. Besides, the meter-out opening ratios $K_{1}$ and $K_{4}$ are used to regulate the output forces $F_{1}$ and $F_{4}$. 


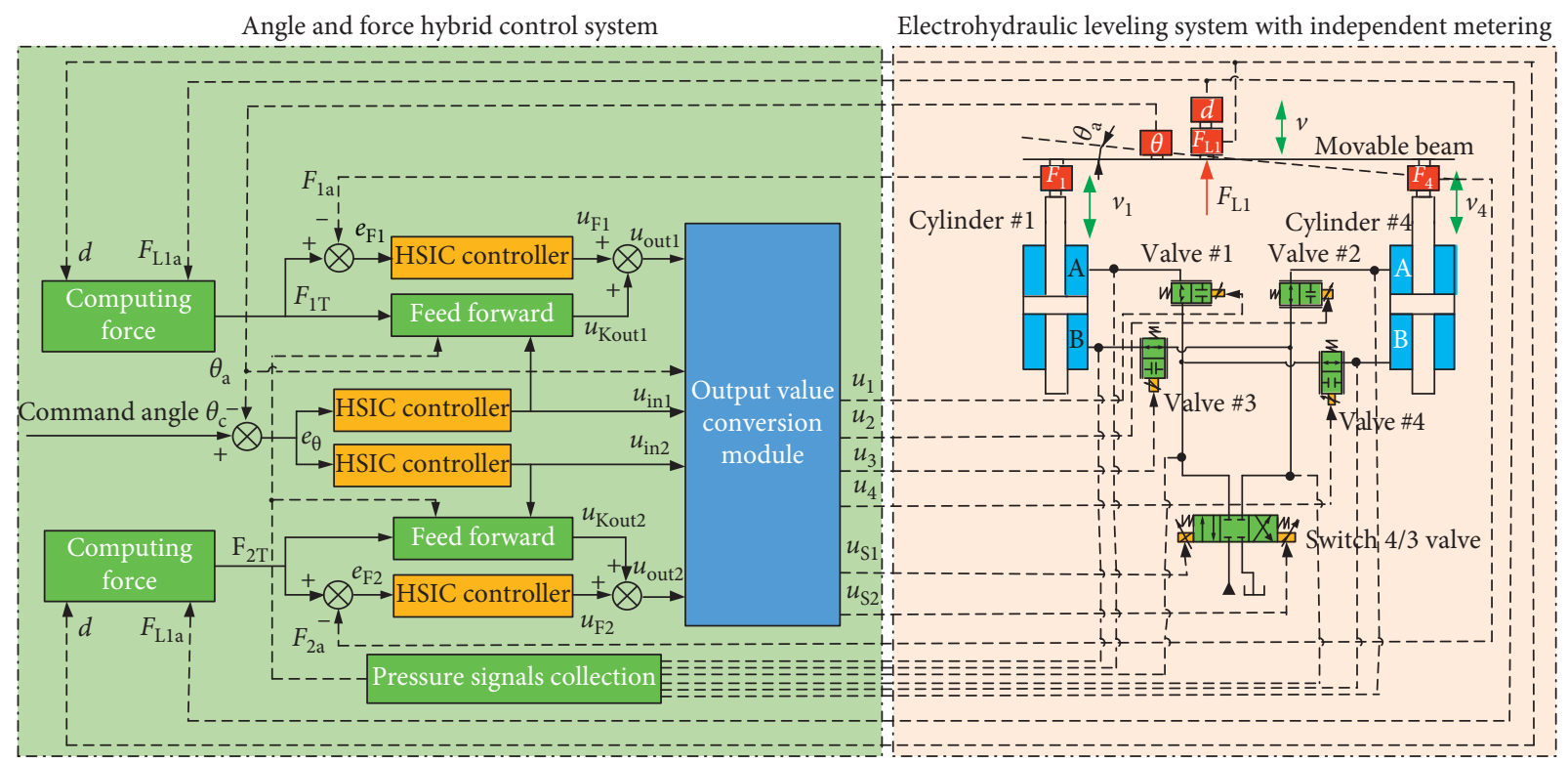

FIgURE 8: Overall angle and force hybrid control strategy.

Consequently, whether in the clockwise leveling condition or counterclockwise leveling condition, the first step of the leveling angle control strategy is making a difference between the command angle $\theta_{\mathrm{c}}$ and the inclination angle $\theta_{\mathrm{a}}$, then takes the error $e_{\theta}$ into two HSIC controllers, and outputs the two values $u_{\text {in } 1}$ and $u_{\text {in } 2}$ for the meter-in opening ratios.

4.2.2. HSIC Controller. Due to the nonlinearities and parameter uncertainties of the electric hydraulic system, it is difficult for the PID controller to achieve a better control effect because the proportional coefficient $k_{\mathrm{p}}$, integral coefficient $k_{\mathrm{i}}$, and differential coefficient $k_{\mathrm{d}}$ are invariant. Therefore, the HSIC (human-simulated intelligent control) is implemented for leveling angle control. The key idea of the HSIC is to imitate people's behavior according to the actual working condition. The HSIC concludes direct control level, parameter correction level, and task adjustment level. The direct control level and parameter correction level are adopted in this study due to the fewer tasks. The characteristic models of the HSIC controller are shown in Figure 9. In Figure $9, e_{1}, e_{2}$, and $e_{3}$ are the threshold values of the error, and $e_{\mathrm{s} 1}, e_{\mathrm{s} 2}$, and $e_{\mathrm{s} 3}$ are the threshold values of the derivation of the error.

The direct control level selects the appropriate control modes according to the error. The characteristic models of the direct control level can be expressed:

$$
\phi_{\mathrm{D}}=\left\{\varphi_{\mathrm{D} 1}, \varphi_{\mathrm{D} 2}, \varphi_{\mathrm{D} 3}, \varphi_{\mathrm{D} 4}\right\},
$$

where $\varphi_{\mathrm{D} 1}: \quad 0 \leq \operatorname{abs}(e)<e_{1}$ and $0 \leq \operatorname{abs}\left(e^{\prime}\right)<e_{\mathrm{s} 1} ; \quad \varphi_{\mathrm{D} 2}$ : $0 \leq \operatorname{abs}(e)<e_{2}$, not including $\varphi_{\mathrm{D} 1} ; \varphi_{\mathrm{D} 3}: e_{2} \leq \operatorname{abs}(e)<e_{3} ; \varphi_{\mathrm{D} 4}$ : $e_{3} \leq \operatorname{abs}(e)<e_{3}$; and abs $(\cdot)$ means the absolute value of the variable in bracket.

There are four control modes of the direct control level according to the characteristic models:

$$
\psi_{\mathrm{D}}=\left\{\psi_{\mathrm{D} 1}, \psi_{\mathrm{D} 2}, \psi_{\mathrm{D} 3}, \psi_{\mathrm{D} 4}\right\},
$$

where $\psi_{\mathrm{D} 1}$ is the zero output mode; $\psi_{\mathrm{D} 2}$ is the derivation control mode; $\psi_{\mathrm{D} 3}$ is the proportional plus derivation control mode; and $\psi_{\mathrm{D} 4}$ is the maintenance control mode.

According to the characteristic models and control modes, the parameters adjustment mode of the direct control level can be expressed as

$$
\Omega_{\mathrm{D}}=\left\{\omega_{\mathrm{D} 1}, \omega_{\mathrm{D} 2}, \omega_{\mathrm{D} 3}, \omega_{\mathrm{D} 4}\right\},
$$

where $\omega_{\mathrm{D} 1}$ : if $\varphi_{\mathrm{D} 1}$ then $\psi_{\mathrm{D} 1} ; \omega_{\mathrm{D} 2}$ : if $\varphi_{\mathrm{D} 2}$ then $\psi_{\mathrm{D} 2} ; \omega_{\mathrm{D} 3}$ : if $\varphi_{\mathrm{D} 3}$ then $\psi_{\mathrm{D} 3} ; \omega_{\mathrm{D} 4}$ : if $\varphi_{\mathrm{D} 4}$ then $\psi_{\mathrm{D} 4}$.

The parameter correction level aims to adaptively adjust the control parameters by imitating the human's experience. The characteristic models of the parameter correction level are chosen as follows:

$$
\phi_{\mathrm{P}}=\left\{\varphi_{\mathrm{P} 1}, \varphi_{\mathrm{P} 2}, \varphi_{\mathrm{P} 3}, \varphi_{\mathrm{P} 4}, \varphi_{\mathrm{P} 5}, \varphi_{\mathrm{P} 6}\right\},
$$

where $\varphi_{\mathrm{P} 1}: 0 \leq \operatorname{abs}\left(e^{\prime}\right)<e_{\mathrm{s} 1}$ and $e e^{\prime} \geq 0 ; \varphi_{\mathrm{P} 2}: 0 \leq \operatorname{abs}\left(e^{\prime}\right)<e_{\mathrm{s} 1}$ and $\left(e e^{\prime} \leq 0\right) ; \varphi_{\mathrm{P} 3}: e_{\mathrm{s} 1} \leq \mathrm{abs}\left(e^{\prime}\right)<e_{\mathrm{s} 2}$ and $e e^{\prime} \geq 0 ; \varphi_{\mathrm{P} 4}$ : $e_{\mathrm{s} 1} \leq \operatorname{abs}\left(e^{\prime}\right)<e_{\mathrm{s} 2}$ and $\left(e e^{\prime} \leq 0\right) ; \varphi_{\mathrm{P} 5}: e_{\mathrm{s} 2} \leq \operatorname{abs}\left(e^{\prime}\right)$ and $e e^{\prime} \geq 0$; and $\varphi_{\mathrm{P} 6}: e_{\mathrm{s} 2} \leq \mathrm{abs}\left(e^{\prime}\right)$ and $\left(e e^{\prime} \leq 0\right)$.

The parameters correction rule is designed for the proportional coefficient $k_{\mathrm{p}}$ and differential coefficient $k_{\mathrm{d}}$ according to the control modes of the direct control level as follows:

$$
\psi_{\mathrm{P}}=\left\{\psi_{\mathrm{P} 1}, \psi_{\mathrm{P} 2}, \psi_{\mathrm{P} 3}, \psi_{\mathrm{P} 4}, \psi_{\mathrm{P} 5}, \psi_{\mathrm{P} 6}, \psi_{\mathrm{P} 7}, \psi_{\mathrm{P} 8}\right\},
$$

where $\psi_{\mathrm{P} 1}: k_{p}\left(t_{i}\right)=k_{p}\left(t_{i-1}\right) ; \psi_{\mathrm{P} 2}: k_{p}\left(t_{i}\right)=\operatorname{MIN}\left(k_{p}\left(t_{i-1}\right) /\right.$ $\left.k_{1}, k_{\mathrm{p} \max }\right) ; \psi_{\mathrm{P} 3}: k_{p}\left(t_{i}\right)=\operatorname{MAX}\left(k_{\mathrm{pmin}}, k_{p}\left(t_{i-1}\right), k_{1}\right) ; \psi_{\mathrm{P} 4}: k_{p}\left(t_{i}\right)$ $=a_{1}+b_{1}\left(1-\operatorname{sech}\left(e\left(t_{i}\right) c_{1}\right)\right) ; \quad \psi_{\mathrm{P} 5}: \quad k_{d}\left(t_{i}\right)=k_{d}\left(t_{i-1}\right) ; \quad \psi_{\mathrm{P} 6}$ : $k_{d}\left(t_{i}\right)=\operatorname{MIN}\left(k_{d}\left(t_{i-1}\right) / k_{2}, k_{\mathrm{d} \max }\right) ; \psi_{\mathrm{P} 7}: k_{d}\left(t_{i}\right)=\operatorname{MAX}\left(k_{\mathrm{dmin}}\right.$, $\left.k_{d}\left(t_{i-1}\right) k_{2}\right) ; \psi_{\mathrm{P} 8}: k_{d}\left(t_{i}\right)=a_{2}+b_{2} /\left(1+\exp \left(e\left(t_{i}\right) d_{2}\right) c_{2}\right) ;$ and the coefficients $k_{1}, k_{2}, k_{\mathrm{pmin}}, k_{\mathrm{pmax}}, k_{\mathrm{d} \min }, k_{\mathrm{dmax}}, a_{1}, b_{1}, c_{1}, a_{2}$, $b_{2}, c_{2}$, and $d_{2}$ are the constant values. 


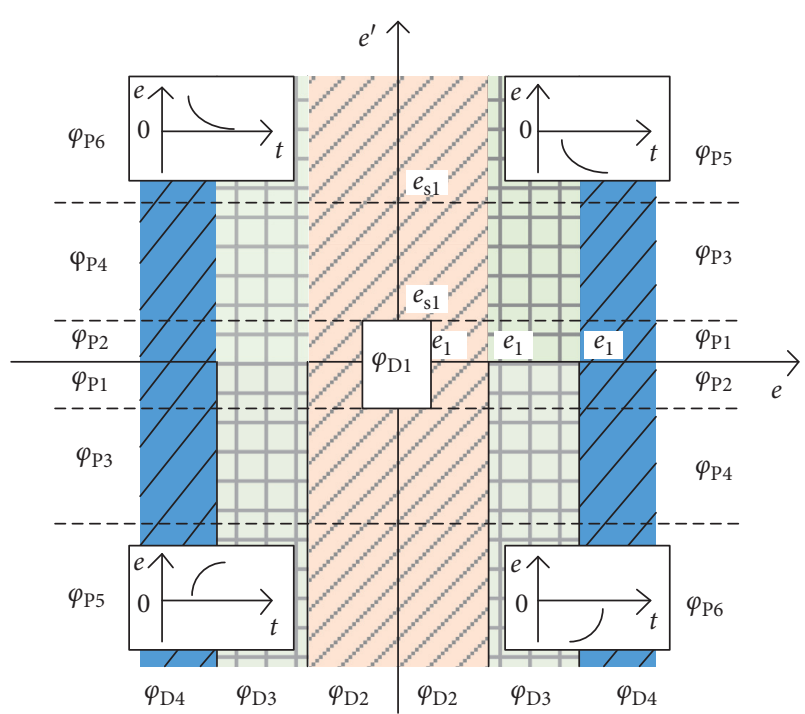

FIgure 9: Characteristic models of the HSIC controller.

The parameters adjustment rules of the parameter correction level can be expressed:

$$
\Omega_{\mathrm{P}}=\left\{\omega_{\mathrm{P} 1}, \omega_{\mathrm{P} 2}, \omega_{\mathrm{P} 3}, \omega_{\mathrm{P} 4}, \omega_{\mathrm{P} 5}, \omega_{\mathrm{P} 6}, \omega_{\mathrm{P} 7}, \omega_{\mathrm{P} 8}, \omega_{\mathrm{P} 9}, \omega_{\mathrm{P} 10}\right\},
$$

where $\omega_{\mathrm{P} 1}$ : if $\varphi_{\mathrm{D} 1}$ or $\varphi_{\mathrm{D} 4}$, then $\psi_{\mathrm{P} 1}$ and $\psi_{\mathrm{P} 5} ; \omega_{\mathrm{P} 2}$ : if $\varphi_{\mathrm{D} 2}$ and $\left(\varphi_{\mathrm{P} 1}\right.$ or $\left.\varphi_{\mathrm{P} 2}\right)$, then $\psi_{\mathrm{P} 1}$ and $\psi_{\mathrm{P} 7} ; \omega_{\mathrm{P} 3}$ : if $\varphi_{\mathrm{D} 2}$ and $\varphi_{\mathrm{P} 3}$, then $\psi_{\mathrm{P} 1}$ and $\psi_{\mathrm{P} 5} ; \omega_{\mathrm{P} 4}$ : if $\varphi_{\mathrm{D} 2}$ and $\left(\varphi_{\mathrm{P} 4}\right.$ or $\left.\varphi_{\mathrm{P} 5}\right)$, then $\psi_{\mathrm{P} 1}$ and $\psi_{\mathrm{P} 8}$; $\omega_{\mathrm{P} 5}$ : if $\varphi_{\mathrm{D} 2}$ and $\varphi_{\mathrm{P} 6}$, then $\psi_{\mathrm{P} 1}$ and $\psi_{\mathrm{P} 6} ; \omega_{\mathrm{P} 6}$ : if $\varphi_{\mathrm{D} 3}$ and $\left(\varphi_{\mathrm{P} 1}\right.$ or $\left.\varphi_{\mathrm{P} 2}\right)$, then $\psi_{\mathrm{P} 1}$ and $\psi_{\mathrm{P} 7} ; \omega_{\mathrm{P} 7}$ : if $\varphi_{\mathrm{D} 3}$ and $\varphi_{\mathrm{P} 3}$, then $\psi_{\mathrm{P} 4}$ and $\psi_{\mathrm{P} 5}$; $\omega_{\mathrm{P} 8}$ : if $\varphi_{\mathrm{D} 3}$ and $\varphi_{\mathrm{P} 4}$, then $\psi_{\mathrm{P} 4}$ and $\psi_{\mathrm{P} 8} ; \omega_{\mathrm{P} 9}$ : if $\varphi_{\mathrm{D} 3}$ and $\varphi_{\mathrm{P} 5}$, then $\psi_{\mathrm{P} 2}$ and $\psi_{\mathrm{P} 5} ; \omega_{\mathrm{P} 10}$ : if $\varphi_{\mathrm{D} 3}$ and $\varphi_{\mathrm{P} 6}$, then $\psi_{\mathrm{P} 3}$ and $\psi_{\mathrm{P} 6}$.

4.3. Force Control Strategy Design. Equations (3) and (4) show that the output forces $F_{1}$ and $F_{4}$ are controlled separately by the leveling cylinders \#1 and \#4 which can overcome the decomposed load force $F_{\mathrm{L} 1}$ along the axis $x$. Therefore, the control strategies of the forces $F_{1}$ and $F_{4}$ are the same, but the adjustment coefficients are different. The force control strategy consists of computing force module, HSIC controller module, pressure signals collection module, and feed forward module.

The aim of the computing force module is computing the target output force $F_{1 \mathrm{~T}}$ or $F_{4 \mathrm{~T}}$ according to (3) or (4). The decomposed load forces $F_{\mathrm{L} 1 \mathrm{a}}$ and $F_{\mathrm{L} 2 \mathrm{a}}$ and the distance $d$ of (3) or (4) can be detected by the sensors. The HSIC controller is adopted in the force control strategy; it is the same as the HSIC controller of the leveling angle control strategy. Correspondingly, the input signal of the HSIC controller is the difference between the target force $F_{1 \mathrm{~T}}$ or $F_{2 \mathrm{~T}}$ and the actual output force $F_{1 \mathrm{a}}$ or $F_{2 \mathrm{a}}$. The output signal of the HSIC controller is the $u_{\mathrm{F} 1}$ or $u_{\mathrm{F} 2}$ which is the compensation value of the meter-out opening ratio. In order to improve the response time of the control system, force feed forward is adopted. The aim of the feed forward is computing the input signal $u_{\text {Kout } 1}$ or $u_{\text {Kout } 2}$ of the meterout proportional $2 / 2$ valves according to (20) or (21). The pressures $P_{\mathrm{A} 1}, P_{\mathrm{A} 2}, P_{\mathrm{a}}$, and $P_{\mathrm{b}}$ of $(20)$ and $(21)$ can be measured by the pressure signals collections module. Take the leveling cylinder \#1 for example; if the proportional valve \#1 is the meter-in valve, then the proportional valve \#3 is the meter-out valve, and vice versa. Then add the $u_{\mathrm{F} 1}$ and $u_{\text {Kout } 1}$, and take the output value $u_{\text {out } 1}$ to the output value conversion module. The obtaining method of the output value $u_{\text {out } 2}$ is the same as that of $u_{\text {out } 1}$. As a result, the meter-out opening ratios $u_{\text {out1 }}$ and $u_{\text {out2 }}$ have been obtained for the output forces $F_{1}$ and $F_{4}$.

4.4. Output Value Conversion Module Design. From the above mentioned analysis, there are two leveling conditions and a horizontal condition. The two leveling conditions are the clockwise leveling condition and the counterclockwise leveling condition. As listed in Table 1, the conversion relationship between the output and input values of the output value conversion module is designed.

From Table 1, it can be seen that the leveling condition can be judged by the actual leveling angle $\theta_{\mathrm{a}}$. When the actual leveling angle $\theta_{\mathrm{a}}$ equals 0 , the movable beam does not need leveling control, so the output values $u_{\mathrm{s} 1}, u_{\mathrm{s} 2}, u_{1}, u_{2}$, $u_{3}, u_{4}$, and $u_{5}$ must be set to 0 . When the actual leveling angle $\theta_{\mathrm{a}}$ is great than 0 , the leveling condition is clockwise leveling condition, so the output values $u_{\mathrm{s} 1}, u_{\mathrm{s} 2}, u_{1}, u_{2}, u_{3}$, $u_{4}$, and $u_{5}$ must be set to the values shown in Table 1 . When the actual leveling angle $\theta_{\mathrm{a}}$ is less than 0 , the leveling condition is counterclockwise leveling condition, so the output values $u_{\mathrm{s} 1}, u_{\mathrm{s} 2}, u_{1}, u_{2}, u_{3}, u_{4}$, and $u_{5}$ must be set to the values shown in Table 1 . As a result, the input and output values are converted by the output value conversion module.

\section{Simulation Model}

In this section, the simulation models are carried out using the AMESim and MATLAB/Simulink software to evaluate the designed overall angle and force hybrid control strategy for electrohydraulic leveling system with independent metering. The AMESim/Simulink cosimulation model of the electrohydraulic leveling system with independent metering is developed as is shown in Figure 10.

According to the hydraulic circuit principle and mechanical principle, the simulation model of the electrohydraulic leveling system with independent metering is built by the AMESim software, as is shown in Figure 10(a). The AMESim simulation model is mainly composed of four types of components; they are hydraulic components, mechanical components, signal components, and cosimulation interface. The hydraulic components of AMESim simulation model include two leveling cylinders, four proportional $2 / 2$ valves, one switch $4 / 3$ valve, six pressure sensors, one pressure signal source, and the tank. The mechanical components are simulating the tilting movement of the movable beam, including one connector, one lever, one force source, two force sensors, and two displacement sensors. The signal components include input pressure signal, load force signal, distance signal, and angle calculation module. The 
TABLE 1: The conversion relationship between the input and output values.

\begin{tabular}{|c|c|c|}
\hline$\theta_{\mathrm{a}}$ & Leveling conditions & Output value \\
\hline \multirow{6}{*}{$>0$} & \multirow{6}{*}{ Clockwise leveling condition } & $u_{\mathrm{s} 1}=1$ \\
\hline & & $u_{\mathrm{s} 2}=0$ \\
\hline & & $u_{1}=u_{\text {in } 1}$ \\
\hline & & $u_{2}=u_{\text {out } 2}$ \\
\hline & & $u_{3}=u_{\text {out } 1}$ \\
\hline & & $u_{4}=u_{\text {in } 2}$ \\
\hline \multirow{6}{*}{$<0$} & \multirow{6}{*}{ Counterclockwise leveling condition } & $u_{\mathrm{s} 1}=0$ \\
\hline & & $u_{\mathrm{s} 2}=1$ \\
\hline & & $u_{1}=u_{\text {out } 2}$ \\
\hline & & $u_{2}=u_{\text {in } 2}$ \\
\hline & & $u_{3}=u_{\text {in } 1}$ \\
\hline & & $u_{4}=u_{\text {out } 2}$ \\
\hline \multirow{6}{*}{$=0$} & \multirow{6}{*}{ Horizontal condition } & $u_{\mathrm{s} 1}=0$ \\
\hline & & $u_{\mathrm{s} 2}=0$ \\
\hline & & $u_{1}=0$ \\
\hline & & $u_{2}=0$ \\
\hline & & $u_{3}=0$ \\
\hline & & $u_{4}=0$ \\
\hline
\end{tabular}

AMESim simulation model cannot directly measure the actual inclination angle $\theta_{\mathrm{a}}$, so take an indirect method to measure the angle $\theta_{\mathrm{a}}$. The indirect method is to take the moving displacement $x$ measured by the displacement sensors and the constant distance $l$ into (5), and then the actual inclination angle $\theta_{\mathrm{a}}$ can be obtained. In order to limit the maximum actual inclination angle $\theta_{\mathrm{a}}$, the minimum and maximum displacements of the leveling cylinders are set as $-0.025 \mathrm{~m}$ and $0.025 \mathrm{~m}$, respectively. The AMESim/Simulink interface is used for data exchange between AMESim and Simulink.

The angle and force hybrid control simulation model is built by MATLAB/Simulink software, as is shown in Figure 10(b). The Simulink simulation model is mainly composed of two computing force modules, one command angle module, four HSIC controllers, two pressure signals collection and feed forward modules, an output value conversion module, and one Simulink/AMESim interface.

In the computing force modules, take the distance $d$, the constant distance $l$, and the decomposed load force $F_{\mathrm{L} 1 \mathrm{a}}$ or $F_{\text {L2a }}$ into (3) or (4), and the target output force $F_{1 \mathrm{~T}}$ or $F_{4 \mathrm{~T}}$ can be obtained. The command angle must be set to 0 by the command angle module. According to the above mentioned principle of HSIC controller, the HSIC controller module is built by using the S-Function. The HSIC controller can be replaced by the traditional PID controller. The pressure signals collection and feed forward module is built by using the embedded MATLAB function. The function of the pressure signals collection and feed forward module is collecting the pressure signals and computing the input signal $u_{\text {Kout } 1}$ or $u_{\text {Kout } 2}$ according to (20) or (21). The output value conversion module is built by the embedded MATLAB function according to the above mentioned designed principle. The Simulink/AMESim interface is used for data exchange between Simulink and AMESim.

\section{Simulation Results and Discussion}

The AMESim simulation model is built according to the electrohydraulic leveling system with independent metering. Therefore, the parameters of the simulation results can be represented as shown in Figure 7. In order to compare the characteristics of the HSIC controller and PID controller, the two controllers are taken into simulation research. The total simulation time is $10 \mathrm{~s}$, the movable beam is inclined due to the external load force in the 1-10 s, and the leveling control starts from the $10 \mathrm{~s}$ to $20 \mathrm{~s}$.

The results of the chambers pressure of the leveling cylinders \#1 and \#4 can be obtained as shown in Figures 11-14.

Figures 11 and 12 show the pressures $P_{\mathrm{A} 1}$ and $P_{\mathrm{B} 1}$ of the leveling cylinder \#1, respectively. It is clear that the pressures $P_{\mathrm{A} 1}$ and $P_{\mathrm{B} 1}$ are varying nearly at 0 from $0 \mathrm{~s}$ to $10 \mathrm{~s}$. When the load force is acting on the movable beam at $10 \mathrm{~s}$, the pressures $P_{\mathrm{A} 1}$ and $P_{\mathrm{B} 1}$ are suddenly changing a lot. Finally, the pressures $P_{\mathrm{A} 1}$ and $P_{\mathrm{B} 1}$ are stabilized at $5 \mathrm{MPa}$ and $0 \mathrm{MPa}$, respectively. Figures 11 and 12 also show that the pressure fluctuation of HSIC controller is smaller than that of the PID controller from $10 \mathrm{~s}$ to $14 \mathrm{~s}$.

Figures 13 and 14 show the pressures $P_{\mathrm{A} 2}$ and $P_{\mathrm{B} 2}$ of the leveling cylinder \#4, respectively. It can be seen that the pressure $P_{\mathrm{A} 2}$ is varying nearly at 0 from $0 \mathrm{~s}$ to $10 \mathrm{~s}$, and the pressure $P_{\mathrm{B} 2}$ is varying nearly at $0.5 \mathrm{MPa}$ from $0 \mathrm{~s}$ to $10 \mathrm{~s}$. The pressures $P_{\mathrm{A} 2}$ and $P_{\mathrm{B} 2}$ are suddenly changing a lot at $10 \mathrm{~s}$ when the load force is acting on the movable beam and finally reach 0 and $5 \mathrm{MPa}$, respectively. From Figures 13 and 14 , it can be also seen that the pressure fluctuation of HSIC controller is smaller than that of the PID controller from $10 \mathrm{~s}$ to $13 \mathrm{~s}$.

The results of the output forces of the leveling cylinder \#1 and \#4 can be obtained as shown in Figures 15 and 16 . Figures 15 and 16 show that when the simulation time is from $0 \mathrm{~s}$ to $10 \mathrm{~s}$, the output forces of the HSIC controller and the PID controller are the same. Finally, the output force $F_{1 \mathrm{a}}$ of leveling cylinder $\# 1$ is reaching $-1.58 \mathrm{MN}$ which is the computing force $F_{1 \mathrm{~T}}$, and the output force $F_{2 \mathrm{a}}$ of leveling cylinder \#4 is reaching $-1.62 \mathrm{MN}$ which is the computing force $F_{2 \mathrm{~T}}$. It can be seen that the final output forces of the leveling cylinders \#1 and \#4 are different, so the electrohydraulic leveling system with independent metering is different from the traditional electrohydraulic leveling system; as a result, it is beneficial to the elimination of the eccentric load force. Moreover, compared with the PID controller, the output forces of the HSIC controller have higher rapidity and smaller overshoot when the load force is acting on the movable beam.

The results of the displacements of the cylinders \#1 and \#4 can be obtained as shown in Figures 17 and 18. Figure 17 shows that the piston of leveling cylinder \#1 is retracting form $0 \mathrm{~s}$ to $2 \mathrm{~s}$, and then it reaches the maximum value $-0.025 \mathrm{~m}$ until $10 \mathrm{~s}$. Figure 18 shows that the piston of leveling cylinder \#4 is extending from $0 \mathrm{~s}$ to $2 \mathrm{~s}$, and then it reaches the maximum value $0.025 \mathrm{~m}$ until $10 \mathrm{~s}$. Then, the leveling control system is starting to work at $10 \mathrm{~s}$, the piston of leveling cylinder \#1 is extending, and the piston of leveling 


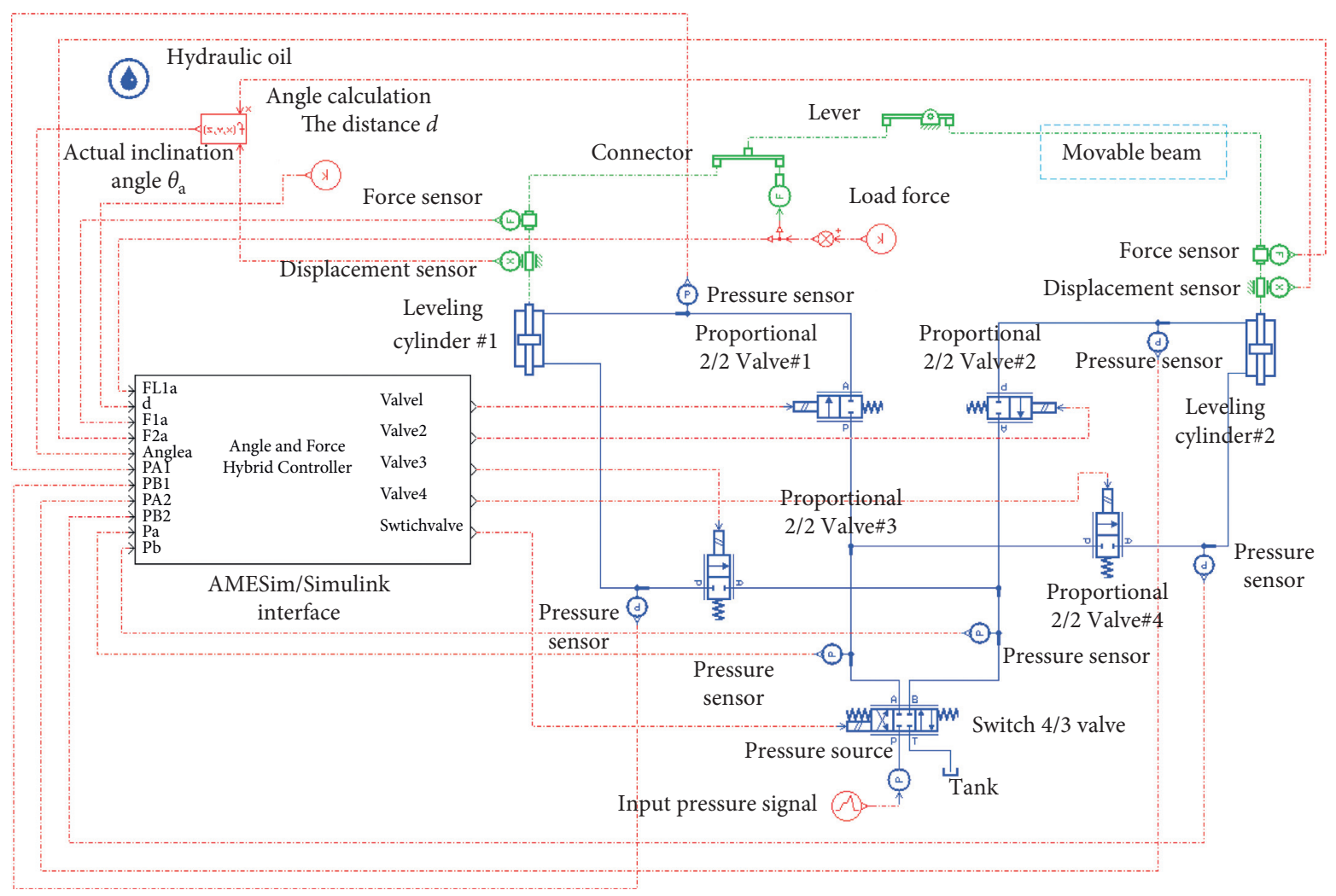

(a)

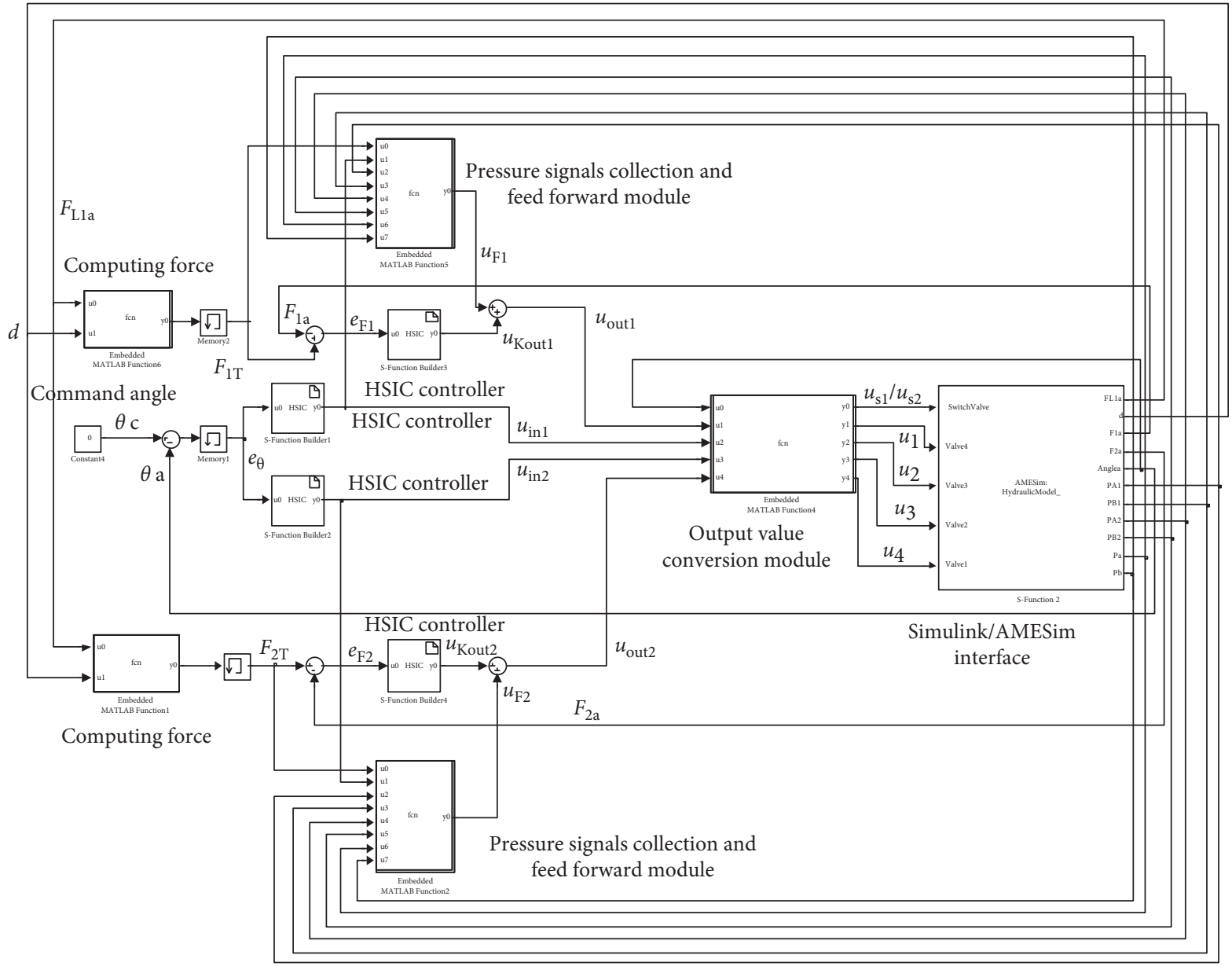

(b)

FIGURE 10: Developed AMESim/Simulink cosimulation model: (a) AMESim simulation model; (b) Simulink simulation model. 


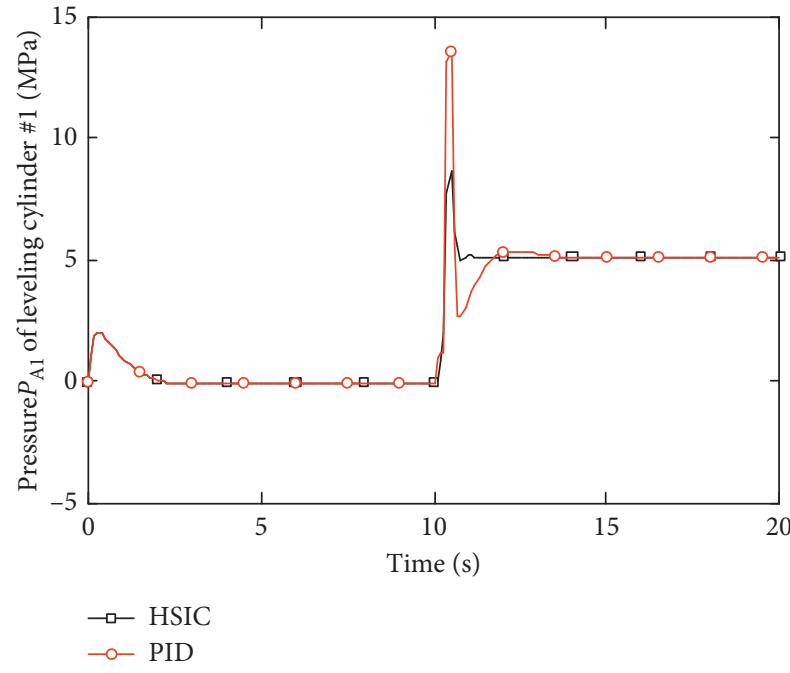

Figure 11: Pressure $P_{\mathrm{A} 1}$ of leveling cylinder \#1.

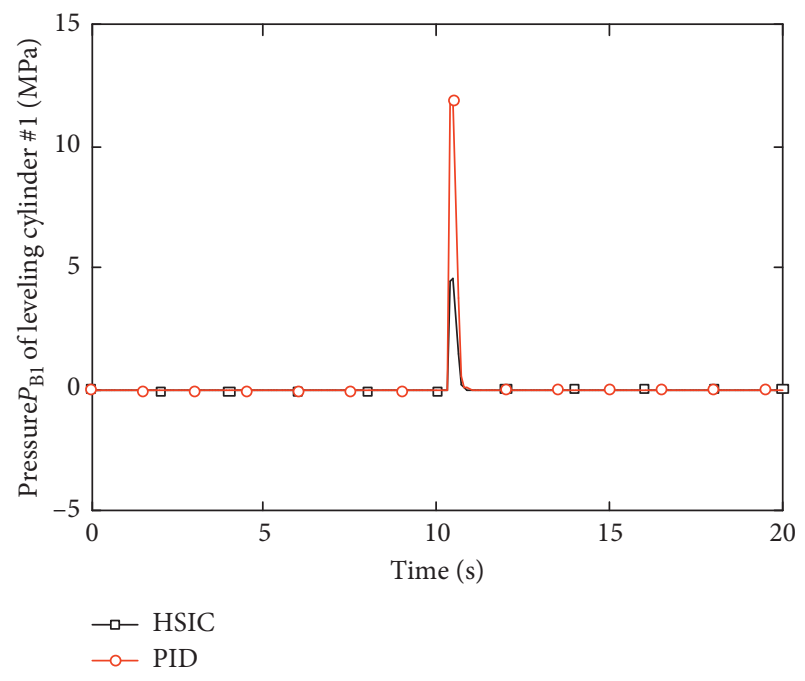

FIgURE 12: Pressure $P_{\mathrm{B} 1}$ of leveling cylinder $\# 1$.

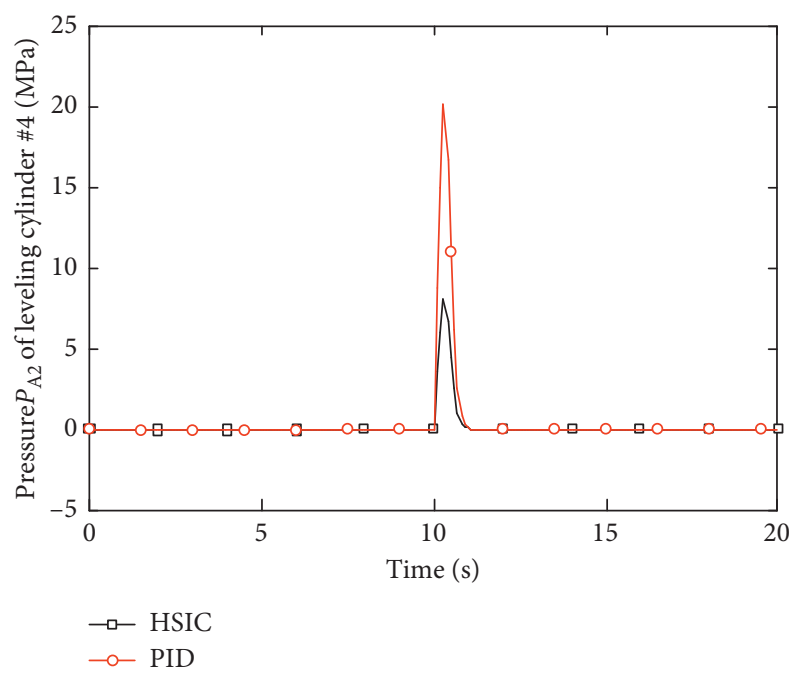

FIgURe 13: Pressure $P_{\mathrm{A} 2}$ of leveling cylinder \#4.

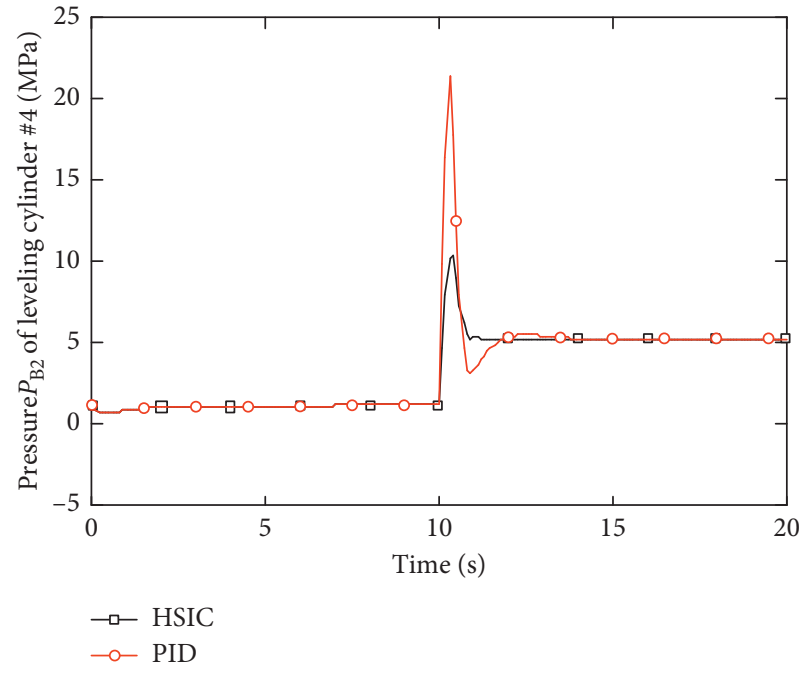

Figure 14: Pressure $P_{\mathrm{B} 2}$ of leveling cylinder \#4.

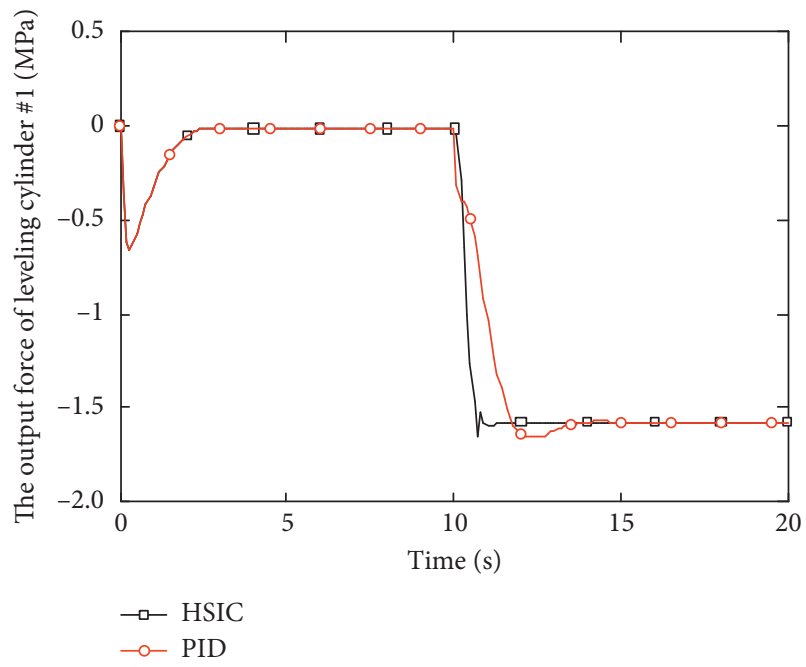

FIgURE 15: The output force $F_{1 \mathrm{a}}$ of leveling cylinder \#1.

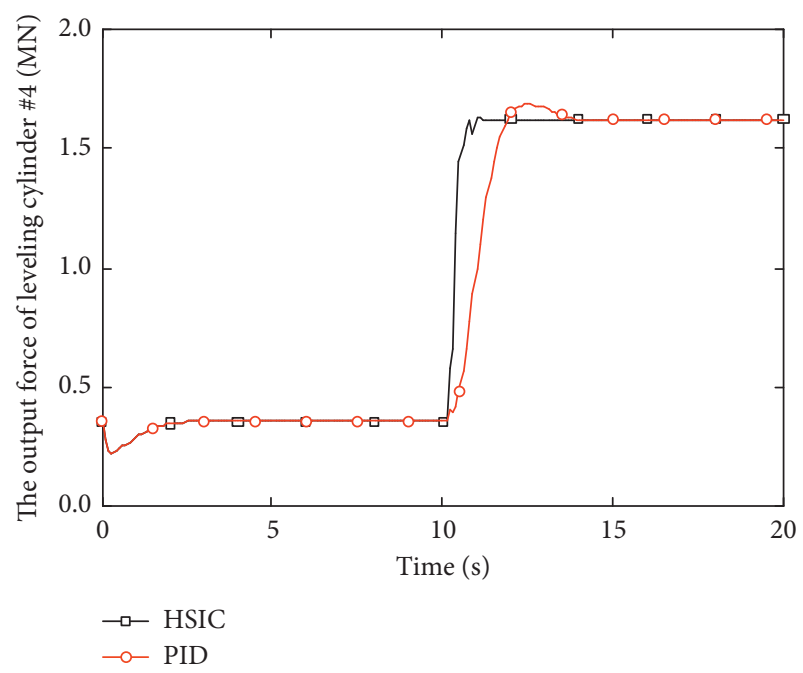

FIgURE 16: The output force $F_{2 \mathrm{a}}$ of leveling cylinder $\# 4$. 


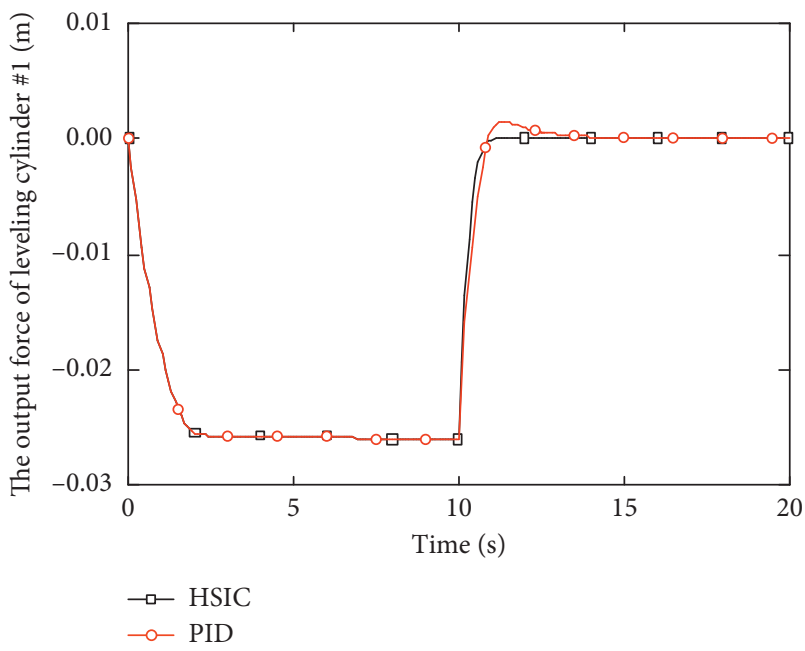

Figure 17: The displacement of leveling cylinder \#1.

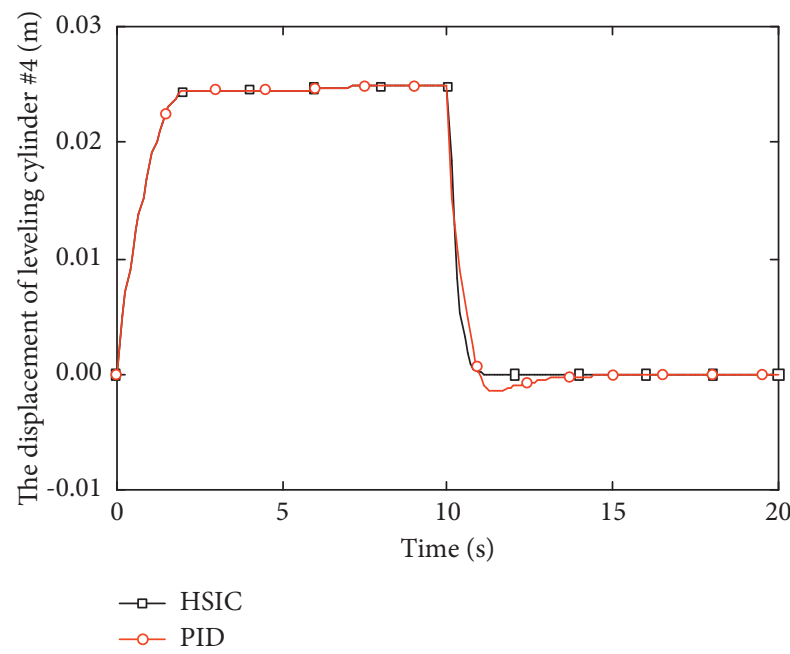

Figure 18: The displacement of leveling cylinder \#4.

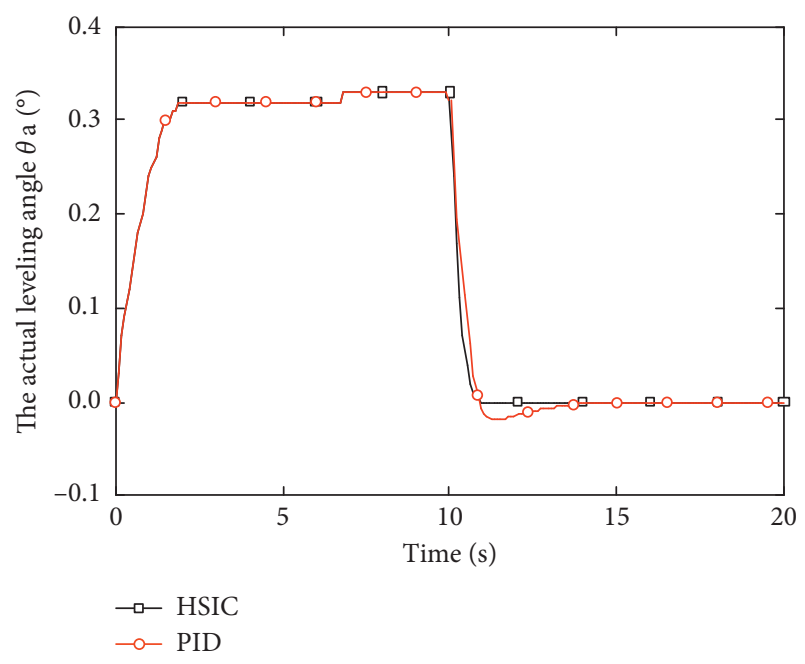

Figure 19: The actual leveling angle $\theta_{\mathrm{a}}$. cylinder \#4 is retracting with about $2 \mathrm{~s}$ and finally reaches $0 \mathrm{~m}$. The HSIC controller and PID controller are used in the simulations; it can be seen that the HSIC controller has higher rapidity and smaller overshoot.

The actual leveling angle $\theta_{\mathrm{a}}$ of the movable beam can be seen in Figure 19. It is clear form Figure 19 that the actual leveling angle $\theta_{\mathrm{a}}$ is beginning to incline from $0^{\circ}$ to more than $0.3^{\circ}$ with $2 \mathrm{~s}$, and then it is stabilizes at $0.32^{\circ}$ from $2 \mathrm{~s}$ to $10 \mathrm{~s}$. After that, the actual leveling angle $\theta_{\mathrm{a}}$ is restored at 0 with about $2 \mathrm{~s}$; as a result, the movable beam is maintaining balance position. It also can be seen that the HSIC controller has higher rapidity and smaller overshoot than the PID controller.

\section{Conclusion}

In order to eliminate the eccentric load force accurately, the electrohydraulic leveling system with independent metering is designed, and then the angle and force hybrid control method applied in the AMESim/Simulink cosimulation model is presented to analyze the dynamic and static characteristics. The following conclusions are obtained from the simulation results:

(1) Compared with the traditional leveling hydraulic control system, the different output forces of leveling cylinders can be obtained by the proposed leveling system, so it is beneficial to the elimination of the eccentric load force.

(2) Both the leveling angle control and leveling cylinders output forces control can be realized, simultaneously, by the angle and force hybrid control method.

(3) Aiming at obtaining the leveling angle and output forces hybrid control effects, the HSIC controller has higher rapidity and smaller overshoot than the PID controller.

This study focuses on the electrohydraulic leveling system design and the angle and force hybrid control method. In addition, enormous work on hybrid control of nonlinear systems requires subsequent study, for example, adaptive finite-time output-feedback control design and observer-based adaptive finite-time tracking control for the electrohydraulic leveling system with independent metering.

\section{Data Availability}

The data used to support the findings of this study are included within the article.

\section{Conflicts of Interest}

The authors declare that they have no conflicts of interest.

\section{Acknowledgments}

This research was supported by Youth Program of National Natural Science Foundation of China (Grant no. 51805228), Natural Science Fund for Colleges and Universities in 
Jiangsu Province (Grant No. 18KJB460010), and IndustryUniversity-Research Cooperation Project of Jiangsu Science and Technology Department (Grant no. BY2019136).

\section{References}

[1] H. Huang, X. Zou, L. Li, X. Li, and Z. Liu, "Energy-saving design method for hydraulic press drive system with multi motor-pumps," International Journal of Precision Engineering and Manufacturing-Green Technology, vol. 6, no. 2, pp. 223234, 2019.

[2] Y. Xu, Z. Teng, J. Yao, Y. Zhou, and Y. Zhao, "Elastodynamic analysis of a novel motion-decoupling forging manipulator," Mechanism and Machine Theory, vol. 147, Article ID 103771, 2020.

[3] J.-M. Zheng, S.-D. Zhao, and S.-G. Wei, "Fuzzy iterative learning control of electro-hydraulic servo system for SRM direct-drive volume control hydraulic press," Journal of Central South University of Technology, Journal of Central South University of Technology, vol. 17, no. 2, pp. 316-322, 2010.

[4] L. Li, H. Huang, X. Li, and Z. Liu, "An improved energy matching method to utilize the potential energy of large-sized hydraulic press at multi-system level," Procedia CIRP, vol. 61, pp. 547-552, 2017.

[5] W. K. Yeung, J. P. Li, K. He, Y. X. Luo, C. T. Kong, and R. Du, "Control system design for a new servo press," in Proceedings of the 17th World Congress on the International Federation of Automatic Control, pp. 5782-5787, Seoul, South Korea, July 2008.

[6] J. Komsta, N. Van Oijen, and P. Antoszkiewicz, "Integral sliding mode compensator for load pressure control of diecushion cylinder drive," Control Engineering Practice, vol. 21, no. 5, pp. 708-718, 2013.

[7] J.-C. Renn and C. Tsai, "Development of an unconventional electro-hydraulic proportional valve with fuzzy-logic controller for hydraulic presses," The International Journal of Advanced Manufacturing Technology, vol. 26, no. 1-2, pp. 10-16, 2005.

[8] O. T. Adenuga and K. Mpofu, "Control system for electrohydraulic synchronization on RBPT," Procedia CIRP, vol. 17, pp. 835-840, 2014.

[9] Q. Lai, L. Liang, J. Li, S. Wu, and J. Liu, "Modeling and analysis on cushion characteristics of fast and high-flow-rate hydraulic cylinder," Mathematical Problems in Engineering, vol. 2016, Article ID 2639480, 17 pages, 2016.

[10] A. Jansson and J. O. Palmberg, "Separate controls of meter-in and meter-out orifices in mobile hyraulic systems," $S A E$ Technical Paper, vol. 99, no. 901583, 1990.

[11] B. Eriksson, J.-O. Palmberg, Individual metering fluid power systems: challenges and opportunities," Proceedings of the Institution of Mechanical Engineers, Part I: Journal of Systems and Control Engineering, vol. 225, no. 2, pp. 196-211, 2011.

[12] K. Abuowda, I. Okhotnikov, S. Noroozi, P. Godfrey, and M. Dupac, "A review of electrohydraulic independent metering technology," ISA Transactions, vol. 98, pp. 364-381, 2020.

[13] S. Liu, B. Yao, Automated onboard modeling of cartridge valve flow mapping," IEEE/ASME Transactions on Mechatronics, vol. 11, no. 4, pp. 381-388, 2006.

[14] H. Hu and Q. Zhang, "Multi-function realization using an integrated programmable $\mathrm{E} / \mathrm{H}$ control valve," Applied Engineering in Agriculture, vol. 11, no. 4, pp. 283-290, 2003.
[15] R. Ding, B. Xu, J. Zhang, and M. Cheng, "Self-tuning pressurefeedback control by pole placement for vibration reduction of excavator with independent metering fluid power system," Mechanical Systems and Signal Processing, vol. 92, pp. 86-106, 2017.

[16] J. Shi, L. Quan, X. Zhang, and X. Xiong, "Electro-hydraulic velocity and position control based on independent metering valve control in mobile construction equipment," Automation in Construction, vol. 94, pp. 73-84, 2018.

[17] K. Liu, Y. Gao, Z. Tu, and P. Lin, "Energy-saving analysis of the independent metering system with pressure compensation for excavator's manipulator," Proceedings of the Institution of Mechanical Engineers, Part I: Journal of Systems and Control Engineering, vol. 230, no. 9, pp. 905-920, 2016. 